Article

\title{
Impact of Future Climate Change on Wheat Production: A Simulated Case for China's Wheat System
}

\author{
Dengpan Xiao ${ }^{1}$, Huizi Bai ${ }^{1, *}$ and De Li Liu ${ }^{2,3, *}$ \\ 1 Engineering Technology Research Center, Geographic Information Development and Application of Hebei, \\ Institute of Geographical Sciences, Hebei Academy of Sciences, Shijiazhuang 050011, China; \\ xiaodp@sjziam.ac.cn \\ 2 NSW Department of Primary Industries, Wagga Wagga Agricultural Institute, \\ Wagga Wagga, NSW 2650, Australia \\ 3 Climate Change Research Centre and ARC Centre of Excellence for Climate Extremes, \\ University of New South Wales, Sydney, NSW 2052, Australia \\ * Correspondence: baihz.13b@igsnrr.ac.cn (H.B.); de.li.liu@dpi.nsw.gov.au (D.L.L.); \\ Tel.: +86-0311-8667-1736 (H.B.); +61-2-6938-1922 (D.L.L.)
}

Received: 10 March 2018; Accepted: 18 April 2018; Published: 21 April 2018 updates

\begin{abstract}
With regard to global climate change due to increasing concentration in greenhouse gases, particularly carbon dioxide $\left(\mathrm{CO}_{2}\right)$, it is important to examine its potential impact on crop development and production. We used statistically-downscaled climate data from 28 Global Climate Models (GCMs) and the Agricultural Production Systems sIMulator (APSIM)-Wheat model to simulate the impact of future climate change on wheat production. Two future scenarios (RCP4.5 and RCP8.5) were used for atmospheric greenhouse gas concentrations during two different future periods (2031-2060 referred to as $40 \mathrm{~S}$ and 2071-2100 referred to as 80S). Relative to the baseline period (1981-2010), the trends in mean daily temperature and radiation significantly increased across all stations under the future scenarios. Furthermore, the trends in precipitation increased under future climate scenarios. Due to climate change, the trend in wheat phenology significantly advanced. The early flowering and maturity dates shortened both the vegetative growth stage (VGP) and the whole growth period (WGP). As the advance in the days of maturity was more than that in flowering, the length of the reproductive growth stage (RGP) of spring wheat was shortened. However, as the advance in the date of maturity was less than that of flowering, the RGP of winter wheat was extended. When the increase in $\mathrm{CO}_{2}$ concentration under future climate scenarios was not considered, the trend in change in wheat production for the baseline declined. In contrast, under increased $\mathrm{CO}_{2}$ concentration, the trend in wheat yield increased for most of the stations (except for Nangong station) under future climatic conditions. Winter wheat and spring wheat evapotranspiration (ET) decreased across all stations under the two future climate scenarios. As wheat yield increased with decreasing water consumption (as ET) under the future climatic conditions, water use efficiency (WUE) significantly improved in the future period.
\end{abstract}

Keywords: adaptation; GCM projection; APSIM model; future climate change; wheat productivity

\section{Introduction}

Global climate change including increasing atmosphere carbon dioxide $\left(\mathrm{CO}_{2}\right)$ concentration, warming temperature, changing surface solar radiation, and variable precipitation is expected to have a significant effect on crop development and production [1-3]. While much has been done in assess the impact of past trends in climate on crop growth and development [4-6], estimates of the potential impact of future climate change on agricultural production and food security remain 
inclusive [7]. Due to the lack of daily climate data (e.g., daily radiation, temperature, and precipitation) on the future conditions, it is hard to conclusively demonstrate site-specific impact assessments of future climate change on crop production [8]. The effect of possible changes in future climatic conditions is a significant uncertainty that deserves further attention for integrated assessments of climate change [9-11]. So far, the extent of yield loss resulting from future climate change in any one particular region still remains unclear [12].

While Global Climate Models (GCMs) can be used to project future climatic conditions [13], crop models can also be used to simulate crop growth processes and yields [14]. It is therefore possible to assess the impact of future climate change on crop production through the joint use of GCMs and crop models $[15,16]$. Generally, the simulation of future climate change scenarios by GCMs is much more complex [17] given the various interactions between the meteorological, physical, and biogeochemical factors of changing atmospheric composition and radiative forcing [18]. Moreover, GCMs output data cannot directly be used in site-specific impacts of climate change on crops due to the coarse spatial and temporal resolutions of GCMs output [19]. Therefore, spatio-temporal scale mismatches between the GCMs and crop simulation models must be bridged through downscaling [20]. This can be achieved either by dynamic or statistical downscaling to obtain high resolution or site-specific climate data [21]. Compared with dynamic downscaling, statistical downscaling is more widely used in climatic studies due to its relatively lower computing resource requirements and ability to incorporate observations into the method [22]. Additionally, the use of statistical downscaling in climate change studies allows for the exploration of the effects of changes in mean climate, climatic variability, and extreme events [23].

In this study, we used the statistical downscaling method proposed by Liu and Zuo [24], which uses a stochastic weather generator to obtain daily and site-specific data from multiple GCMs under various future emission scenarios [8]. It accounted for uncertainties in future climatic conditions by using two scenarios of future atmospheric greenhouse gas concentrations. The statistical downscaling method was used to downscale GCM projections from the Coupled Model Intercomparison Project Phase 5 (CMIP5) ensemble to a local scale. The climate change impact analysis involved the statistical downscaling of climate projections of $28 \mathrm{GCMs}$ [8] under two emission scenarios (RCP4.5 and RCP8.5) to drive the Agricultural Production Systems sIMulator (APSIM) model.

China is the highest wheat producer in the world, producing about $120.4 \mathrm{Mt}$ annually [25]. The North China Plain (NCP) is the primary winter wheat (with summer maize rotation)-producing area in China, accounting for over 50\% of China's wheat production [26]. However, due to low temperatures during the winter period (November to January) in Northern China (NC), wheat is a seasonal crop grown only once a year [27]. Therefore, spring wheat (sown in spring season) is the staple crop cultivated in NC [28]. In this study, an attempt was made to use climate change scenario data from the GCMs output as input for the process-based crop models used to assess the impact of future climate change on wheat production. The main aim of this study was to evaluate the impact of future climate change on wheat production across wheat cropping regions, including in both the spring (in NC) and winter wheat (in the NCP) systems in China.

\section{Materials and Methods}

\subsection{Study Site}

The study area was located in typical spring wheat in NC [28] and winter wheat in NCP [6] growing zones in China (Figure 1). A total of eight stations, representing different agro-climatic zones across the wheat belt, were selected for the study (Figure 1). In the NC region, four Agro-Meteorological Experiment Stations (AMES)—Hami station in Xinjiang Autonomous Region (XJ), Wuwei station in Gansu Province (GS), Haixi station in Qinhai Province (QH), and Pingluo station in Ningxia Autonomous Region (NX)-were selected for spring wheat data collection (Figure 1). Another four AMES-Tangshan and Nangong stations in Hebei Province (HB), Huimin station in Shandong Province (SD), and Zhumadian in Henan Province (HN) - were used for experiments and data collection in 
the NCP region for winter wheat (Figure 1). All the selected stations were geographically and climatologically different and had good records on weather/crop variables. The general information on the crops and stations used in the study is summarized in Table 1.

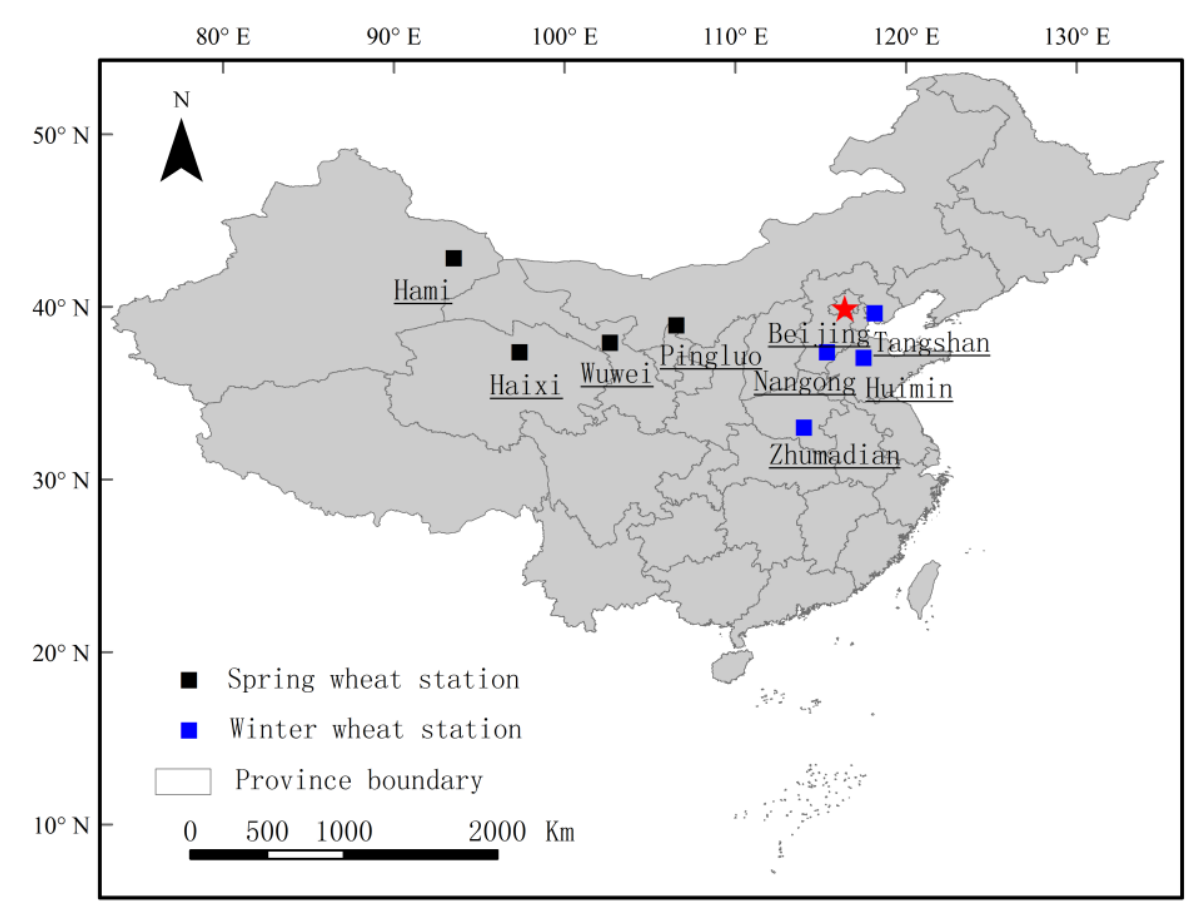

Figure 1. Locations of the investigated agro-meteorological experimental stations in China.

\subsection{Climate and Crop Data}

Climate data are required to drive APSIM and to correct biases in GCM outputs as part of the statistical downscaling procedure. Historical daily climate data (including maximum (Tmax) and minimum temperature (Tmin), sunshine hours (Sh), and precipitation (Prec)) for the baseline period of 1960-2010 were obtained for the eight representative agro-meteorological stations from China's Meteorological Administration (CMA). Daily solar radiation (Rad) for the selected stations was calculated from the sunshine hours using the Angstom-Prescott equation [29].

The Coupled Model Intercomparison Project Phase 5 (CMIP5) simulations include four future socio-economic scenarios referred to as representative concentration pathways (RCP)-i.e., RCP2.6, RCP4.5, RCP6.0, and RCP8.5 [13]. The RCPs are labeled according to the approximate global radiative-forcing level in 2100 with $\mathrm{CO}_{2}$ concentrations reaching 421, 538, 670, and $936 \mathrm{ppm}$ [30]. In this study, we used 28 GCMSs with simulation data available for both RCP4.5 and RCP8.5 [30]. The data for the 28 GCMs (Table 2) for the two different RCPs (RCP4.5 and RCP8.5) were obtained from the CMIP5 data set [8,31]. Gridded fields of monthly mean daily maximum and minimum air temperatures and monthly total radiation and precipitation for the period 1960-2100 were downloaded from the CMIP5 data set for RCP4.5 and RCP8.5 for each of the 28 GCMs [8].

Data for wheat phenology (date of sowing, flowering, and maturity), grain yield, and management practice were also from experiments conducted at the four CMA agro-meteorological stations. Crop management practices at the stations were generally the same as or better than the local traditional practices. The choice of wheat cultivars was based on the major cultivars sowed by the local farmers. There were repeated applications of fertilizers and irrigation during the cultivation seasons (Table 1). With the exception of Zhumadian station, which was maintained under rain-fed conditions, irrigation at the other stations was generally conducted 3-4 times per year for winter wheat and 6-8 times per year for spring wheat. Fertilizer was applied twice per year. In addition, pesticides were used for pest and disease control. 
Table 1. General information of the stations and crop/climate data in the eight investigated stations in China.

\begin{tabular}{|c|c|c|c|c|c|c|c|c|}
\hline Station & Hami & Wuwei & Haixi & Pingluo & Tangshan & Nangong & Huimin & Zhumadian \\
\hline Province & Xinjiang & Gansu & Qinghai & Ningxia & Hebei & Hebei & Shangdong & Henan \\
\hline Latitude $\left({ }^{\circ} \mathrm{N}\right)$ & 42.82 & 37.92 & 37.37 & 38.92 & 39.63 & 37.37 & 37.05 & 33.00 \\
\hline Longitude $\left({ }^{\circ} \mathrm{E}\right)$ & 93.52 & 102.67 & 97.37 & 106.55 & 118.17 & 115.38 & 117.52 & 114.02 \\
\hline Altitude (m) & 737.9 & 1530.8 & 2981.5 & 1099.0 & 25.9 & 27.4 & 11.3 & 82.7 \\
\hline \multicolumn{9}{|l|}{ Crop data } \\
\hline Period of Crop Data & 1991-2001 & 1990-2001 & 1994-2004 & 1996-2006 & $2005-2008$ & $2006-2008$ & 2005-2009 & $2006-2009$ \\
\hline Cultivar & Hachun1 & Yongliang4 & Abo & Yongliang4 & Jingdong 8 & Shimai12 & Lumai23 & Zhengmai9023 \\
\hline Mean Sowing Date (DOY) & 80 (21 March) & 77 (18 March) & 92 (2 April) & 63 (4 March) & 277 (4 October) & 285 (12 October) & 281 (8 October) & 295 (22 October) \\
\hline Mean Flowering Date (DOY) & 162 (11 June) & 163 (12 June) & 194 (13 July) & 160 (9 June) & 132 (12 May) & 122 (2 May) & 126 (6 May) & 104 (14 April) \\
\hline Mean Maturity Date (DOY) & 197 (16 July) & 200 (19 July) & 240 (28 August) & 192 (11 July) & 166 (15 June) & 157 (6 June) & 159 (8 June) & 139 (19 May) \\
\hline Mean Yield (kg ha $\left.{ }^{-1}\right)$ & 5209.9 & 6266.2 & 6422.7 & 4794.0 & 6415.4 & 6442.6 & 6833.2 & 5373.0 \\
\hline \multicolumn{9}{|l|}{ Climate data } \\
\hline Annual Mean Temperature $\left({ }^{\circ} \mathrm{C}\right)$ & 10.3 & 8.5 & 4.4 & 9.0 & 12.8 & 14.0 & 13.5 & 15.7 \\
\hline $\begin{array}{l}\text { Annual Mean Solar Radiation } \\
\left(\mathrm{MJ} \mathrm{m}^{-2}\right)\end{array}$ & 17.0 & 16.3 & 18.2 & 16.8 & 13.9 & 13.3 & 13.6 & 12.1 \\
\hline Annual Total Precipitation (mm) & 42.7 & 170.8 & 199.3 & 167.7 & 587.7 & 454.4 & 538.9 & 999.7 \\
\hline \multicolumn{9}{|l|}{ Management } \\
\hline Irrigation & Irrigation & Irrigation & Irrigation & Irrigation & Irrigation & Irrigation & Irrigation & Rain-fed \\
\hline Fertilizer & $\begin{array}{l}\text { Chemical } \\
\text { fertilizer (N, P, K) }\end{array}$ & $\begin{array}{l}\text { Chemical } \\
\text { fertilizer (N, P, K) }\end{array}$ & $\begin{array}{l}\text { Chemical } \\
\text { fertilizer (N, P, K) }\end{array}$ & $\begin{array}{l}\text { Chemical } \\
\text { fertilizer (N, P, K) }\end{array}$ & $\begin{array}{l}\text { Chemical } \\
\text { fertilizer (N, P, K) }\end{array}$ & $\begin{array}{l}\text { Chemical } \\
\text { fertilizer (N, P, K) }\end{array}$ & $\begin{array}{l}\text { Chemical } \\
\text { fertilizer (N, P, K) }\end{array}$ & $\begin{array}{l}\text { Chemical } \\
\text { fertilizer (N, P, K) }\end{array}$ \\
\hline
\end{tabular}

Note that DOY is day of year. 
Table 2. List of the 28 IPCC AR5 (the Fifth Assessment Report of the Intergovernmental Panel on Climate Change) GCMs (Global Climate Models) used in this study.

\begin{tabular}{lllll}
\hline Model No. & GCM Name & GCM Abbreviation & Institute ID & Country \\
\hline 01 & BBC-CSM1.1 & BC1 & BCC & China \\
02 & BCC-CSM1.1(m) & BC2 & BCC & China \\
03 & BNU-ESM & BNU & GCESS & China \\
04 & CanESM2 & CaE & CCCMA & Canada \\
05 & CCSM4 & CCS & NCAR & USA \\
06 & CESM1(BGC) & CE1 & NSF-DOE-NCAR & USA \\
07 & CMCC-CM & CM2 & CMCC & Europe \\
08 & CMCC-CMS & CM3 & CMCC & Europe \\
09 & CSIRO-Mk3.6.0 & CSI & CSIRO-QCCCE & Australia \\
10 & EC-EARTH & ECE & EC-EARTH & Europe \\
11 & FIO-ESM & FIO & FIO & China \\
12 & GISS-E2-H-CC & GE2 & NASA GISS & USA \\
13 & GISS-E2-R & GE3 & NOSA GISS & USA \\
14 & GFDL-CM3 & GF2 & NOAA GFDL & USA \\
15 & GFDL-ESM2G & GF3 & NOAA GFDL & USA \\
16 & GFDL-ESM2M & GF4 & NIMR/KMA & Korea \\
17 & HadGEM2-AO & Ha5 & INM & Russia \\
18 & INM-CM4 & INC & IPSL & France \\
19 & IPSL-CM5A-MR & IP2 & IPSL & France \\
20 & IPSL-CM5B-LR & IP3 & MIROC & Japan \\
21 & MIROC5 & MI2 & MIROC & Japan \\
22 & MIROC-ESM & MI3 & MIROC & Japan \\
23 & MIROC-ESM-CHEM & MI4 & MPI-M & Germany \\
24 & MPI-ESM-LR & MP1 & MPI-M & Germany \\
25 & MPI-ESM-MR & MP2 & MRI & Japan \\
26 & MRI-CGCM3 & MR3 & NE1 & Norway \\
27 & NorESM1-M & NE2 & Norway \\
28 & NorESM1-ME & & & \\
\hline & & & NCC & COA \\
\hline
\end{tabular}

However, the APSIM model requires the daily time series data of climate observations at each station. Therefore, the data were processed to produce bias-corrected daily time series for the eight stations using the statistical downscaling method developed by [24]. Briefly, monthly GCM output data (solar radiation, precipitation, daily maximum, and minimum temperatures) from 28 GCMs were first downscaled to the observed site scale using the inverse distance-weighted interpolation method $[23,31]$. Biases were then corrected using a transfer function derived from the interpolated GCM data and observed data for the sites [23]. Daily climate data for each site were generated for 1960-2100 using the modified stochastic weather generator (WGEN) [32], with parameters derived from the bias-corrected monthly data [8]. A detailed description of the method is available in [19].

\subsection{APSIM-Wheat Model}

The performance of APSIM has been widely tested and verified for cropping system simulations under different environments including Australia, USA, the Netherlands, North Africa, China, and elsewhere worldwide [26,33]. In this study, APSIM-v7.7 (Agricultural production systems research unit of Australia, Toowoomba, Australia) [34] was used to evaluate the effects of future climate change on wheat yield at eight selected stations (Table 1). APSIM, a cropping systems model, was developed by the Agricultural Production Systems Research Unit of Australia. As the model is component-driven, it can be run for selected modules (e.g., crop growth/development processes and soil water/nitrogen dynamics). APSIM can simulate crop phenological stages, leaf area index (LAI), biomass accumulation, and partitioning and daily growths of root/stem/leaf and grain [35]. In its genetic module, APSIM uses several parameters related to the duration of each growth stage/phase: grain-filling rate, grain size, and photoperiod sensitivity. APSIM requires weather data (e.g., radiation, Tmax, Tmin, and precipitation) 
in daily time-steps and soil hydraulic parameters as inputs. The scientific basis of the simulation approaches used for all functional components are included in the module documentation at the www.apsim.info/APSIMwebsite.

\subsection{Simulation Modelling}

In our simulations, the wheat sowing date was set as the mean sowing date for the past three decades at eight selected stations (Table 1). Sowing density was 120 plants $\mathrm{m}^{-2}$, at a depth of $3 \mathrm{~cm}$. Details of the management practices (fertilization and irrigation) are shown in Table 1. The APSIM-Wheat model was calibrated and validated at the eight representative stations using field-observation data for spring and winter wheat based on the field experimental results $[6,28]$ as listed in Table 1. Overall, the model-simulated and field-observed dates of flowering and maturity agreed well for all investigated stations (Figure 2). The difference between the simulated and observed dates of flowering and maturity was on average less than 5 days. Furthermore, the simulated yield agreed well with the observed values. The average difference between the simulated and observed yields was less than $500 \mathrm{~kg} \mathrm{ha}^{-1}$ (or less than $10 \%$ of the observed values) (Figure 2). Thus, the results of the APSIM model simulation of wheat growth phenology and yield were reliable and therefore applicable.
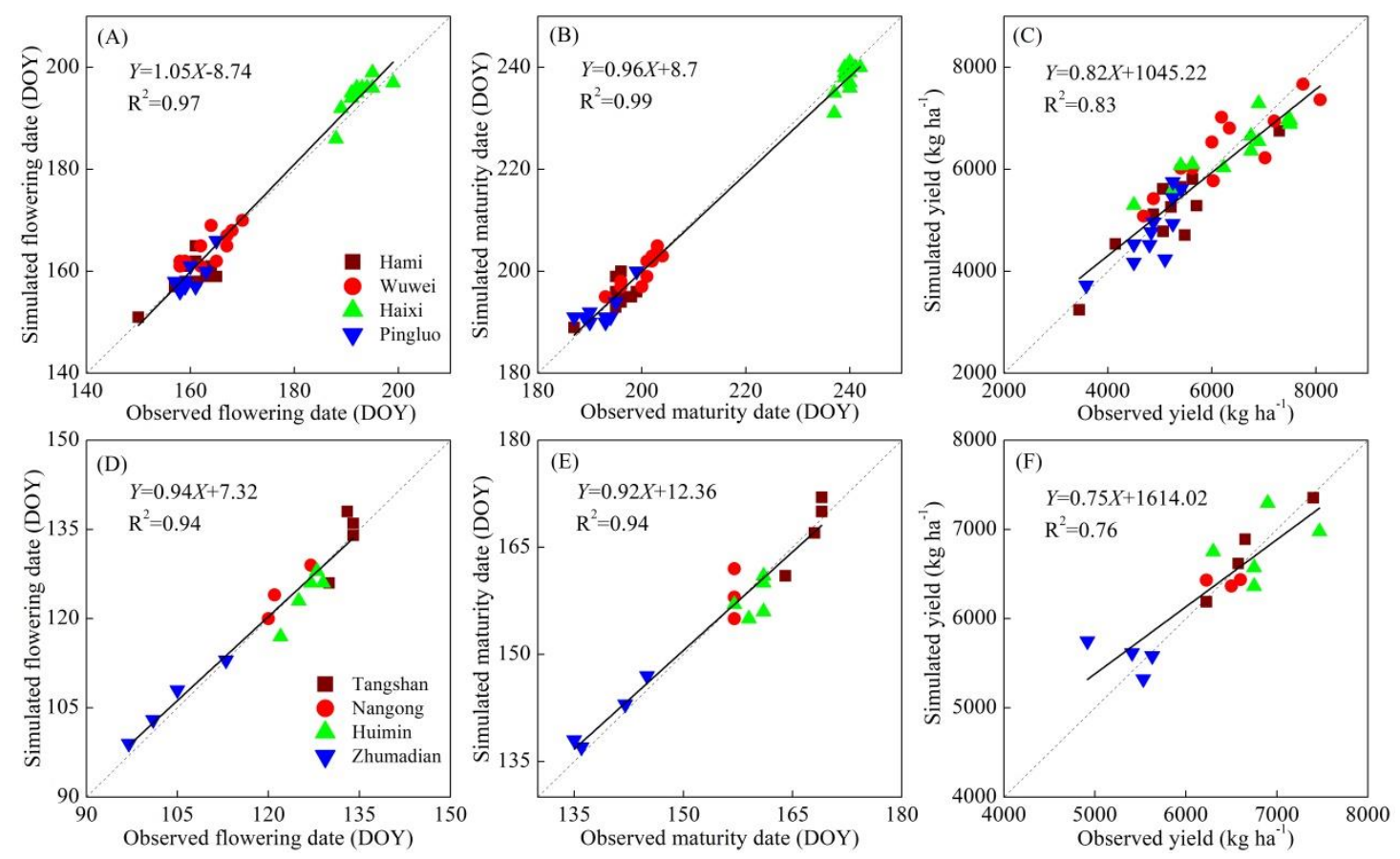

Figure 2. Validation plots of the APSIM-wheat model simulation with observed flowering date, maturity date, and yield for spring $(\mathbf{A}, \mathbf{B}, \mathbf{C})$ and winter wheat $(\mathbf{D}, \mathbf{E}, \mathbf{F})$.

In this study, we mainly focused on the analyses of the impacts of climatic conditions on wheat yield in three different 30-year periods. The first period was from 1981-2010 (referred to as the baseline period) based on historical climate data. The other two periods were 2031-2060 (referred to as the 40S) and 2071-2100 (referred to as the 80S), based on corresponding greenhouse gas emissions and GCM projections. In the three different periods, we used the calibrated crop model (APSIM) to simulate wheat phenology, yield, and evapotranspiration (ET) at the eight selected stations, respectively. To some extent, elevated atmosphere $\mathrm{CO}_{2}$ concentration in future climate change can significantly affect crop growth by influencing radiation use efficiency, transpiration efficiency, and critical leaf nitrogen concentration in APSIM. During the baseline period (1981-2010), we set the $\mathrm{CO}_{2}$ concentration to $380 \mathrm{ppm}$. Furthermore, the yearly atmospheric $\mathrm{CO}_{2}$ concentrations for the two different 30-year periods of future conditions ( $40 \mathrm{~S}$ and $80 \mathrm{~S}$ ) were calculated using empirical functions as $\mathrm{CO}_{2}$ input for 
APSIM [36]. Moreover, to assess the impact of increased future $\mathrm{CO}_{2}$ concentration on wheat yield, we simulated $\mathrm{CO}_{2}$ concentration under no change condition (with $\mathrm{CO}_{2}$ concentration at baseline) and change conditions calculation by empirical functions in the two future periods (40S and 80S), respectively. Finally, water use efficiency (WUE) was defined as WUE = Yield /ET [6].

\section{Results and Analysis}

\subsection{Projected Climate Change}

Figure 3 shows the changes in annual mean daily radiation and temperature (including maximum and minimum temperatures) and mean annual total precipitation for the two future periods of $40 \mathrm{~S}$ (2031-2060) and 80S (2071-2100) over the baseline period (1981-2010) based on the downscaled data from the 28 GCMs under scenarios RCP4.5 and RCP8.5.

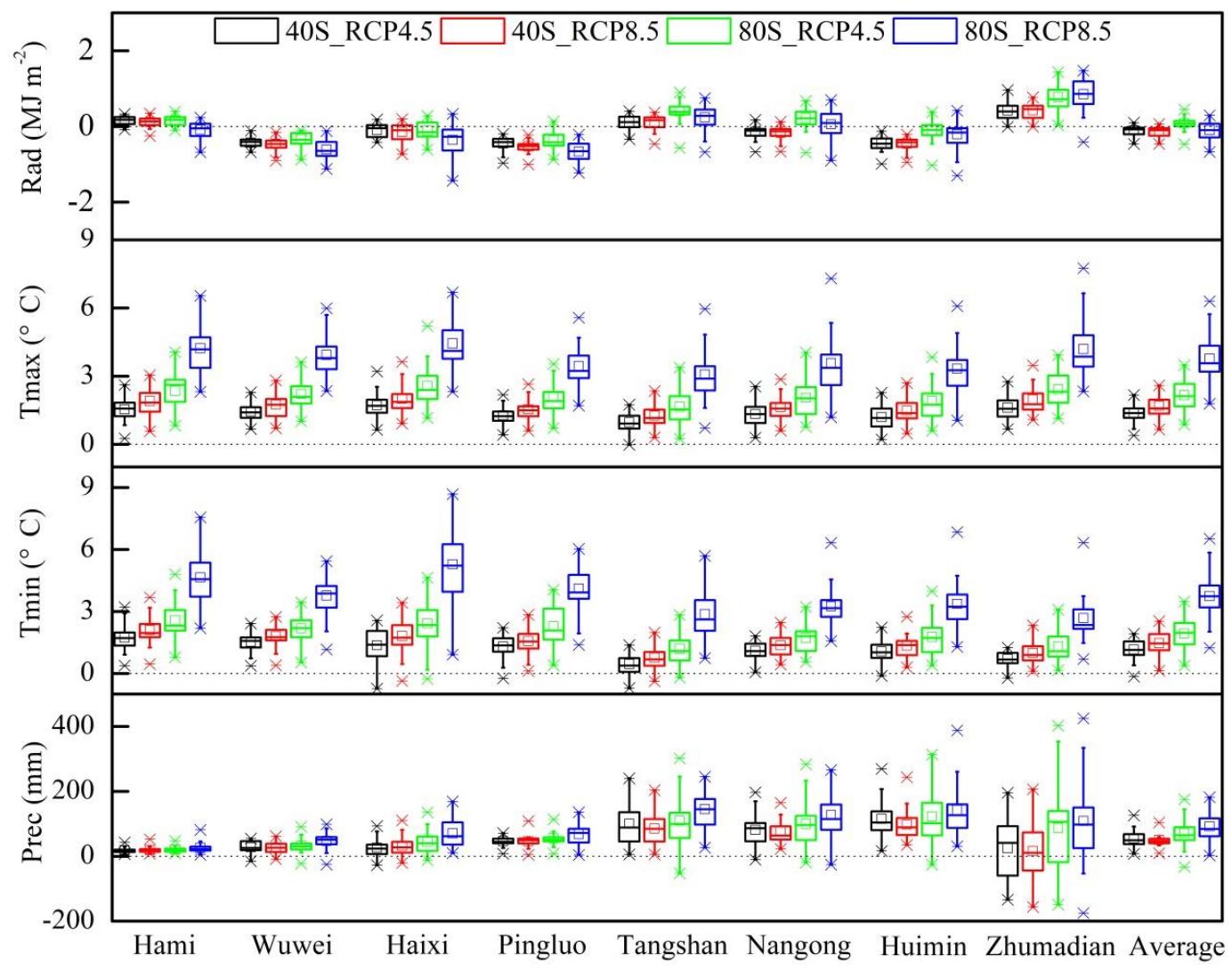

Figure 3. Changes in solar radiation (Rad), maximum temperature (Tmax), minimum temperature (Tmin), and precipitation (Prec) for the 40S (2031-2060) and 80S (2071-2100) with the baseline (1981-2010) periods under RCP4.5 and RCP8.5 conditions.

For solar radiation, there were increasing trends at the Hami (except for 80S_RCP8.5), Tangshan, and Zhumadian stations, while radiation at the Wuwei, Haixi, Pingluo, and Huimin stations decreased under the two future periods ( $40 \mathrm{~S}$ and $80 \mathrm{~S}$ ) and the two scenarios (RCP4.5 and RCP8.5) (Figure 3). At Nangong station, the changes in radiation were complex, with a decreasing trend under the RCP4.5 scenario and an increasing trend under the RCP8.5 scenario (Figure 3). Across the stations, mean daily radiation significantly increased under the future scenarios (except for a slight increase under scenario 40S_RCP8.5) (Figure 3). Hovever, the magnitude of the changes in radiation projected by most of GCMs was less than $1 \mathrm{MJ} \mathrm{m}^{-2}$.

For temperature, the eight stations had increasing trends under future climate scenarios (Figure 3). Furthermore, the increase in temperature under the high-concentration scenario (RCP8.5) was greater than that under the low-concentration scenario (RCP4.5) (Figure 3). Additionally, the trend of increase 
in temperature during $80 \mathrm{~S}$ was bigger than that during 40S. Across the stations, the maximum temperature (Tmax) increased by $1.4{ }^{\circ} \mathrm{C}$ and $2.2^{\circ} \mathrm{C}$ under the two scenarios (RCP4.5 and RCP8.5) during $40 \mathrm{~S}$, respectively, and increased by $1.7^{\circ} \mathrm{C}$ and $3.8^{\circ} \mathrm{C}$ under the two scenarios during $80 \mathrm{~S}$, respectively (Figure 3). The magnitude of the median changes in minimum temperature (Tmin) was slightly lower than that of Tmax under future scenarios (except for the 80S_RCP8.5 scenario). As shown in Figure 3, the average Tmin increased by 1.2 and $1.9^{\circ} \mathrm{C}$ under the two RCP4.5 and RCP8.5 scenarios during $40 \mathrm{~S}$, respectively, while it increased by 1.5 and $3.8^{\circ} \mathrm{C}$ under the two scenarios during $80 \mathrm{~S}$, respectively (Figure 3).

Increases in precipitation were projected by most of more than 75\% of GCM for all stations, except for RCP4.5 and 80S_RCP8.5 at Zhumadian (Figure 3). Moreover, the increases in precipitation projected by the majority of GCMs for the four winter wheat stations were higher than those in the four spring wheat stations (Figure 3). Across the stations, average annual precipitation increased by $20.2 \%$ and $24.8 \%$ under the two RCP4.5 and RCP8.5 scenarios during 40S, respectively, while it increased by $19.8 \%$ and $32.3 \%$ under the two scenarios in 80 , respectively (Figure 3). Moreover, the changes in monthly mean daily radiation and temperature (including the maximum and minimum temperatures) and mean monthly total precipitation for the two future periods of $40 \mathrm{~S}$ and $80 \mathrm{~S}$ are shown in Figures S1-S4.

\subsection{Change in Wheat Phenology}

Results indicated that future climate change could have a significant impact on wheat phenology. Figure 4 shows the changes in flowering and maturity dates during 40S (2031-2060) and 80S (2071-2100) relative to the baseline period (1981-2010) under the RCP4.5 and RCP8.5 scenarios. Under future climate scenarios, there was a significant advancing trend in wheat phenology, with significant differences in phenological response between the stations due to the difference in climatic conditions and climate change (Figure 4). In the two future periods (40S and 80S), the effects of RCP8.5 on phenology were significantly higher than those of RCP4.5. In addition, under the same $\mathrm{CO}_{2}$ concentration scenario, the advance in the days of wheat phenology during $80 \mathrm{~S}$ was higher than that during 40S (Figure 4). As the sowing date remained unchanged for the two simulation periods, the advance in flowering and maturity dates will shorten the vegetative growth stage (VGP) and the whole growth period (WGP) of wheat (Table 3). However, the duration of the reproductive growth stage (RGP) is determined by the extent of advance in flowering and maturity stages. For the 40S_RCP4.5, 40S_RCP8.5, 80S_RCP4.5, and 80S_RCP8.5 scenarios, the RGP of the four spring wheat stations was shortened by 1.0, 1.1, 2.4, and 4.0 days of the 28 GCM average, respectively (Table 3), as the days of maturity advance was more than that of the flowering date. However, as the early trend in maturity date was less than that in the flowering date, the RGP of winter wheat was extended. The RGP of winter wheat was extended by 1.2, 1.6, 1.9, and 4.1 days in the 40S_RCP4.5, 40S_RCP8.5, 80S_RCP4.5, and 80S_RCP8.5 scenarios, respectively (Table 3).

Table 3. Changes in RGP (duration from flowering to maturity) for the 40S (2031-2060) and 80S (2071-2100) periods under RCP4.5 and RCP8.5 conditions.

\begin{tabular}{llllll}
\hline Wheat Type & Station & 40S_RCP4.5 & 40S_RCP8.5 & 80S_RCP4.5 & 80S_RCP8.5 \\
\hline \multirow{5}{*}{ Spring wheat } & Hami & $-1.1 \pm 0.3$ & $-1.4 \pm 0.6$ & $-2.5 \pm 0.8$ & $-2.5 \pm 1.7$ \\
& Wuwei & $-1.4 \pm 0.5$ & $-1.5 \pm 0.5$ & $-1.6 \pm 0.6$ & $-2.3 \pm 0.5$ \\
& Haixi & $-1.4 \pm 1.4$ & $-1.3 \pm 1.1$ & $-5.4 \pm 2.3$ & $-8.9 \pm 2.0$ \\
& Pingluo & $-0.3 \pm 0.4$ & $-0.2 \pm 0.4$ & $-0.1 \pm 0.7$ & $-2.2 \pm 2.9$ \\
& Average & $-1.0 \pm 0.5$ & $-1.1 \pm 0.6$ & $-2.4 \pm 2.2$ & $-4.0 \pm 3.3$ \\
\hline \multirow{5}{*}{ Winter wheat } & Tangshan & $0.0 \pm 0.3$ & $0.1 \pm 0.4$ & $0.3 \pm 0.5$ & $1.4 \pm 0.8$ \\
& Nangong & $0.6 \pm 0.6$ & $0.8 \pm 0.7$ & $1.0 \pm 0.6$ & $2.8 \pm 2.3$ \\
& Huimin & $0.4 \pm 0.5$ & $0.6 \pm 0.6$ & $0.8 \pm 0.8$ & $2.3 \pm 1.6$ \\
& Zhumadian & $3.8 \pm 1.4$ & $5.0 \pm 2.5$ & $5.7 \pm 2.6$ & $9.8 \pm 2.7$ \\
& Average & $1.2 \pm 1.8$ & $1.6 \pm 2.2$ & $1.9 \pm 2.5$ & $4.1 \pm 3.9$ \\
\hline
\end{tabular}

Note that the number after " \pm " is the standard error of the difference (SED) of the respective variable. 


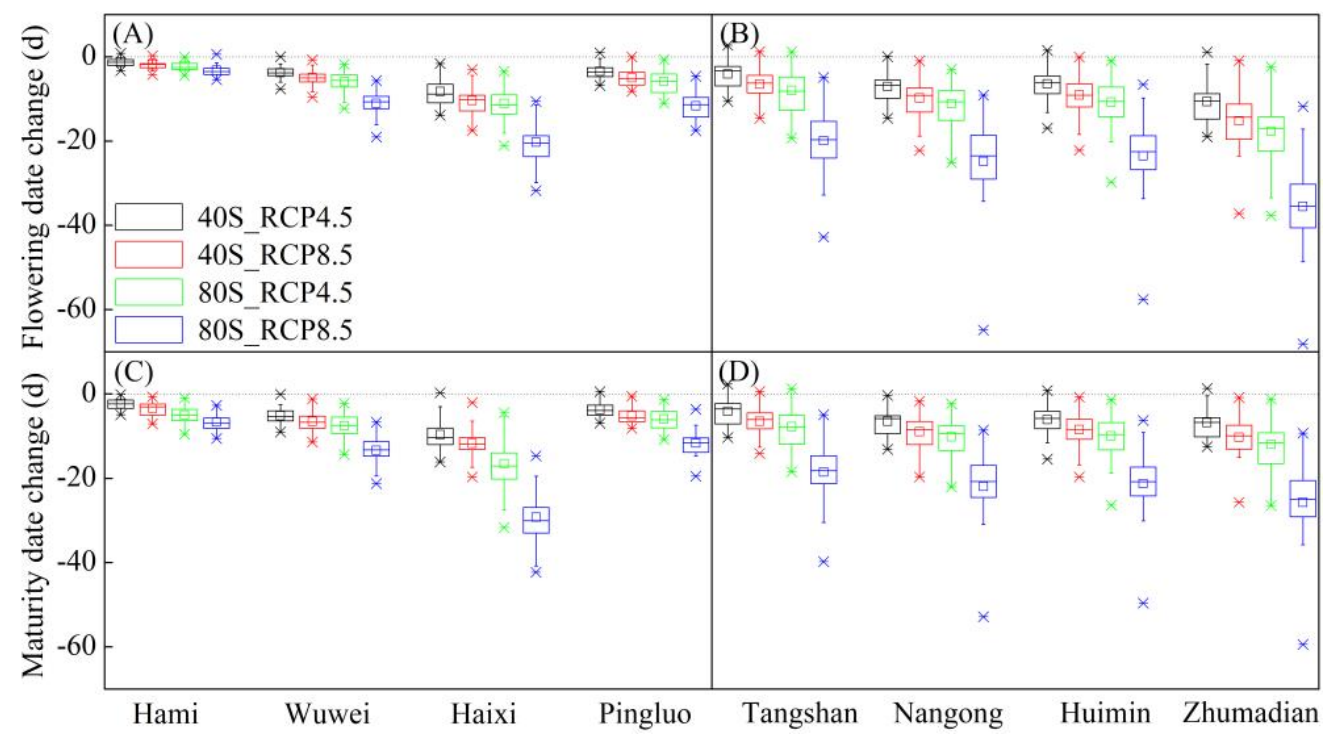

Figure 4. Change in flowering and maturity dates for spring $(\mathbf{A}, \mathbf{C})$ and winter wheat $(\mathbf{B}, \mathbf{D})$ under the four different future climate scenarios.

\subsection{Change in Wheat Yield}

Future climate change mainly includes a change in climatic factors (e.g., radiation, temperature, and precipitation) and an increase in $\mathrm{CO}_{2}$ concentration. In general, an increase in $\mathrm{CO}_{2}$ concentration has a positive effect on crop growth and yield of $\mathrm{C} 3$ plants such as wheat. Sometimes, the impact of change in climatic factors on crop yield is overshadowed or offset by the effects of elevated $\mathrm{CO}_{2}$ concentration. Therefore, in the process of simulating change in wheat yield under future climate scenarios, two simulation settings (with and without increasing $\mathrm{CO}_{2}$ concentration) are used. For constant $\mathrm{CO}_{2}$ concentration, the simulation results give the effect of climate change on yield. Increasing $\mathrm{CO}_{2}$ concentration simulation gives the growth of wheat under actual future conditions. As shown in Figure 5, when $\mathrm{CO}_{2}$ concentration was held constant, the trend in future wheat production declined. The decreases in yield across the various research stations were different. For spring wheat, the yield decrease was largest at Wuwei station, decreasing by averages of $-11.0 \%,-12.7 \%,-16.5 \%$, and $-22.7 \%$ over 28 GCMs under the four climate scenarios 40S_RCP4.5, 40S_RCP8.5, 80S_RCP4.5, and 80S_RCP8.5, respectively. The decrease was lowest at Haixi station, deceasing by averages of $-0.8 \%,-0.9 \%,-0.7 \%$, and $-7.3 \%$ under the four future scenarios, respectively (Figure 5). Meanwhile, the winter wheat yield at Nangong and Zhumadian stations decreased significantly, while that at Tangshan and Huimin stations decreased only slightly (Figure 5). Taking into account the positive effects of rising $\mathrm{CO}_{2}$ concentration on yield, the trend in wheat yield increased for most of the stations (except for Nangong station) under the future climate scenarios. The increase in spring wheat yield was more than that in winter wheat (Figure 5). This suggests that an increase in $\mathrm{CO}_{2}$ concentration will greatly increase wheat yield, which will offset the negative effects of change on wheat yield. This is a significant positive aspect of climate change in relation to crop production. 


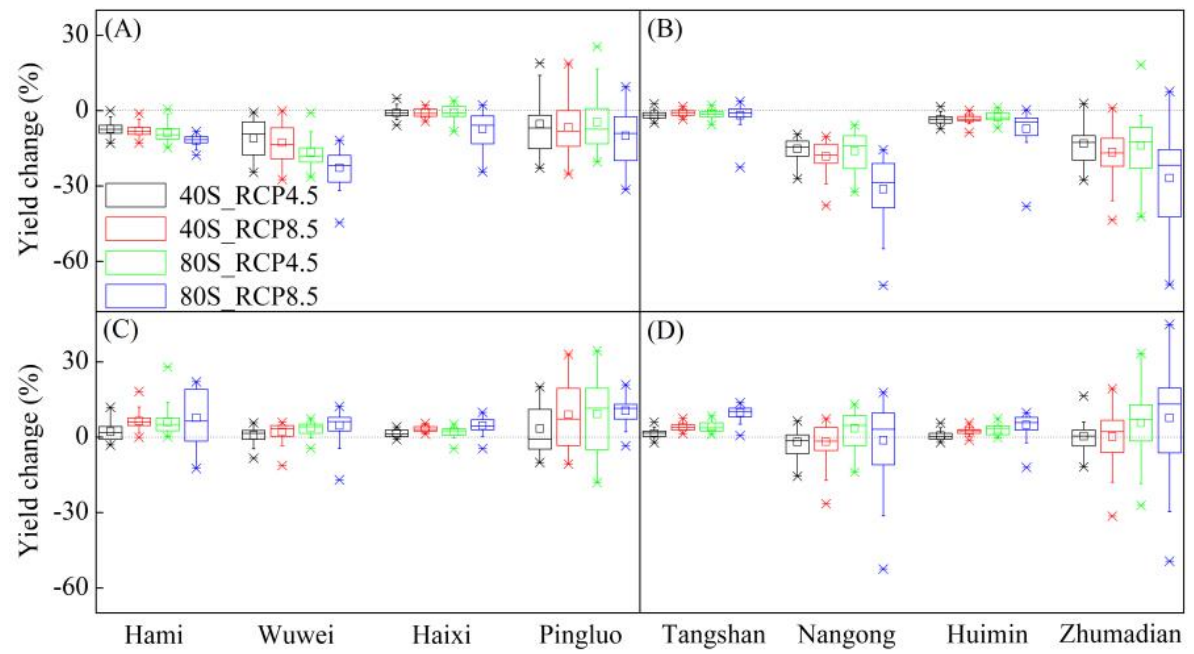

Figure 5. Change in yield for spring wheat $(A, C)$ and winter wheat $(B, D)$ under four different future scenarios with constant $(\mathbf{A}, \mathbf{B})$ and changing $\mathrm{CO}_{2}$ concentrations $(\mathbf{C}, \mathbf{D})$.

\subsection{Change in Evapotranspiration (ET) and Water Use Efficiency (WUE)}

As shown in Figure 6, the ET of winter and spring wheat for all the selected stations was reduced under the two future climate scenarios. Under the same emission scenario, the drop in ET during $80 \mathrm{~S}$ was more than that during 40S. Especially under the 80S_RCP8.5 scenario, the average ET of spring wheat at the four stations decreased by $43.5 \mathrm{~mm}$ (Figure 6), while that of winter wheat decreased by $72.3 \mathrm{~mm}$ (Figure 6). As the wheat yield increased with decreasing water consumption (ET) under future climatic conditions, the water use efficiency (WUE) of wheat significantly improved. Under the four scenarios, while WUE of spring wheat increased, respectively, by an average of $0.5,0.9,1.3$, and $4.1 \mathrm{~kg} \mathrm{~mm}^{-1}$ over $28 \mathrm{GCMs}$, that of winter wheat increased, respectively, by average of $0.5,1.1,1.6$, and $4.3 \mathrm{~kg} \mathrm{~mm}^{-1}$ (Figure 6).

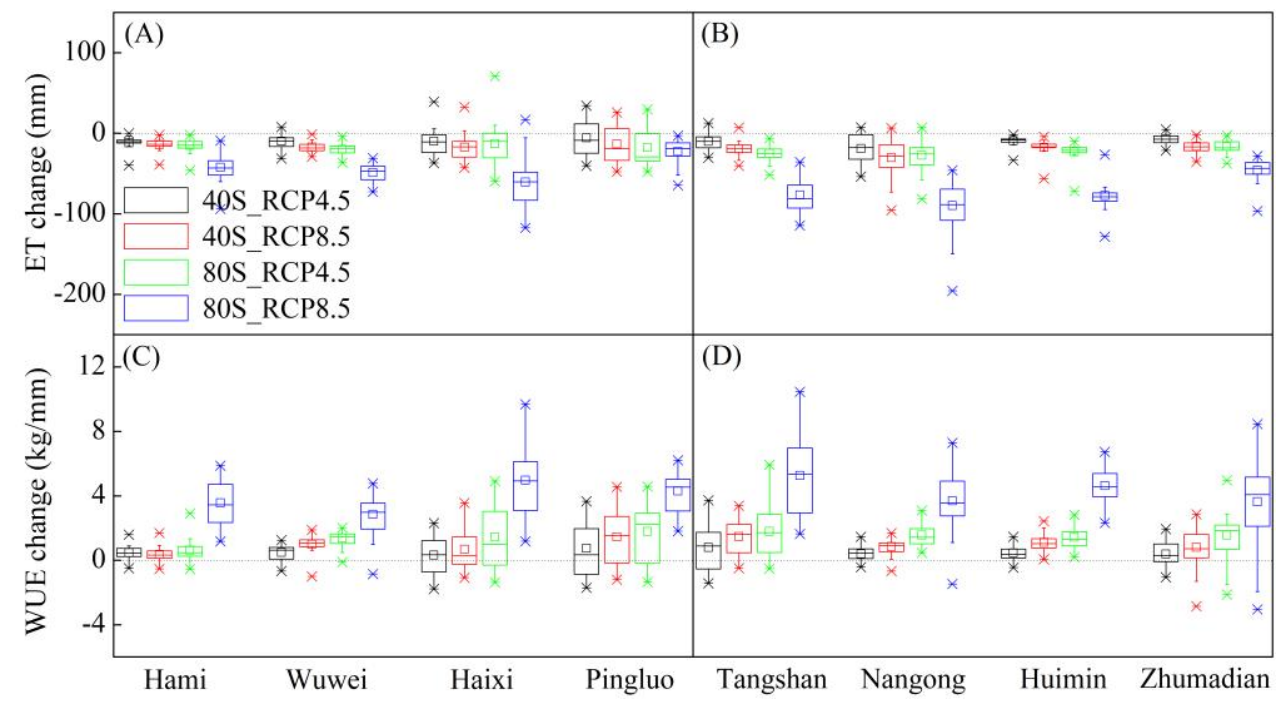

Figure 6. Change in ET and WUE for spring $(\mathbf{A}, \mathbf{C})$ and winter wheat $(\mathbf{B}, \mathbf{D})$ under the four different future climate scenarios.

\section{Discussion}

Any change in climate will have implications for climate-sensitive systems such as agriculture, forestry, and other natural resources [37]. With respect to agriculture, change and variability in climatic 
factors (e.g., solar radiation, temperature, and precipitation) could undoubtedly exert a significant impact on crop phenology and yield [2,38]. Important direct effects will be changes in temperature, precipitation, growing season duration, and timing of extreme or critical threshold events relative to crop development [4]. Furthermore, an increased atmospheric $\mathrm{CO}_{2}$ concentration could have beneficial effects on the growth and productivity of staple food crops [39]. In this study, we assessed the response of wheat to future climate change with respect to solar radiation, temperature, precipitation, and atmospheric $\mathrm{CO}_{2}$ concentration.

We used statistically-downscaled data derived from 28 different GCMs to generate data for future climate scenarios in which there was climate variability across eight stations in China [32]. The use of 28 GCMs was important to capture the uncertainty in future projections that arises from uncertainties in model structure and parameterization [40]. The multi-model mean climate changes from our method were consistent with recently developed climate change projections for China [41]. In the future climate scenarios, temperature was a rising trend. In the future climate scenarios, increasing temperatures resulted in a significant alteration of wheat phenology at each of the eight stations. Generally, higher warming accelerates phenological development [42], resulting in less time to grow over the course of the growing season [43]. Warmer temperatures accelerate phenological development, resulting in less nutrient uptake and radiation interception, consequently lowering biomass production over the course of the growing season [44]. Higher temperatures reduce the length of the growing season, which results in lower biomass production [45]. Increase in temperature mainly shortens the wheat growth period. The results showed that the VGP and WGP of spring and winter wheat during the two future periods (40S and 80S) significantly shortened. Precipitation increased, which improved water conditions during crop growth [46]. However, irrigation measures adopted at the research stations reduced the impact of increasing precipitation on crop production [6]. Change in radiation was relatively complex, with some stations showing an increasing trend and others a decreasing trend. Studies have shown that radiation is not a major limiting factor for spring wheat production in NC [29]. For NCP, however, radiation is an important limiting factor, as it affects the winter wheat yield, especially in low radiation regions such as at Zhumadian station [6,47]. Decreasing radiation over the past few decades has reduced production by about $0.4 \%$ per year at Zhumadian station [6]. In the future climate scenarios, an increase in radiation in NCP positively influenced winter wheat. However, there were also interaction effects of temperature, precipitation, and $\mathrm{CO}_{2}$ concentration on wheat yield [6]. Relative wheat yield changes due to climate change without the effect $\mathrm{CO}_{2}$ fertilization were determined. The results showed that without the influence of increasing $\mathrm{CO}_{2}$ concentration, future climate change decreased spring and winter wheat yield. The main reason for that was the temperature rise, which shortened the wheat growth period and thereby reduced photosynthesis and, consequently, wheat yield [48]. However, wheat as a $\mathrm{C} 3$ plant is more sensitive to $\mathrm{CO}_{2}$ concentration [49]. The increase in $\mathrm{CO}_{2}$ concentration due to future climate change will undoubtedly have a positive effect on wheat production. Whether the $\mathrm{CO}_{2}$ fertilization effect overrides the negative impacts of rising temperature also depends on the magnitude of atmospheric $\mathrm{CO}_{2}$ and the temperature increase in the projected climate [39]. With the combined effects of increased $\mathrm{CO}_{2}$ and climatic factors, wheat yield increased at most of the research stations under the future climate scenarios.

It is important to note that no adaptive management strategies were considered in response to climate change, a clearly unrealistic assumption. Agricultural systems are managed, and farmers always have a number of possible adaptation options [27,50]. These adaptation strategies could potentially reduce future yield losses from climate change or improve yields in regions where beneficial climate change occurs [50,51]. This study did not reflect how yields would change if farmers implemented adaptation measures such as changing planting dates, switching varieties, etc. However, the study did provide a clear picture of the adverse effects of climate change on wheat growth and yield if no adaptation measures to climate change were taken. Furthermore, our results indicated that potential future adaptations to climate change for wheat yields could require either increased tolerance to maximum summer temperatures in existing wheat varieties or a change in 
cultivated wheat varieties. Another strategy was the development of different cultivars that are better adapted to future climatic conditions [52]. With limited time and resources, crop scientists and breeders must select the most appropriate traits for crop improvement and should thereafter focus on the development of wheat cultivars with higher thermal requirements or longer growing seasons [6].

\section{Conclusions}

Future climate change could have a significant impact on agriculture, especially the combined effects of elevated temperature, increased droughts, and reduced crop-water availability. The APSIM wheat simulation model was used to simulate the impact of climate change on wheat yield based on future climate change across wheat cropping regions in China.

We concluded that despite accelerated phenological development and an earlier flowering date in a warming climate across eight stations in China, wheat yield will not decrease with $\mathrm{CO}_{2}$ fertilization. Due to interactions such as higher temperature offsetting the higher $\mathrm{CO}_{2}$-induced yield gains for RCP8.5, higher atmospheric $\mathrm{CO}_{2}$ concentrations under RCP8.5 when compared to RCP4.5 could also offset the increased negative effects of decreased precipitation and shortened growth period. Moreover, mitigating the impacts of future climate change on crop yield is a crucial food security task in the study area. It is beneficial to develop a higher thermal requirement and later maturity cultivars in order to cope with increased heat stress at the flowering stage.

Supplementary Materials: The following are available online at http:/ / www.mdpi.com/2071-1050/10/4/1277/s1, Figure S1: Changes in monthly mean daily radiation (Rad) for the 40S (2031-2060) and 80S (2071-2100) with baseline (1981-2010) periods under RCP4.5 and RCP8.5 conditions; Figure S2. Changes in monthly daily maximum temperature (Tmax) for the 40S (2031-2060) and 80S (2071-2100) with baseline (1981-2010) periods under RCP4.5 and RCP8.5 conditions; Figure S3. Changes in monthly daily minimum temperature (Tmin) for the 40S (2031-2060) and $80 S$ (2071-2100) with baseline (1981-2010) periods under RCP4.5 and RCP8.5 conditions; Figure S4. Changes in mean monthly total precipitation (Prec) for the 40S (2031-2060) and 80S (2071-2100) with baseline (1981-2010) periods under RCP4.5 and RCP8.5 conditions.

Author Contributions: Dengpan Xiao conceived and designed the study; Huizi Bai ran the crop model; De Li Liu collected data; Dengpan Xiao and De Li Liu wrote the paper; and all the authors provided comments on the earlier versions of this manuscript.

Acknowledgments: This research was supported by the Natural Science Foundation of China (41401104) and the Natural Science Foundation of Hebei Province, China (D2015302017).

Conflicts of Interest: The authors declare no conflict of interest.

\section{References}

1. Monteith, J. Climatic variation and the growth of crops. Q. J. R. Meteor. Soc. 1980, 107, 749-774. [CrossRef]

2. Asseng, S.; Foster, I.; Turner, N. The impact of temperature variability on wheat yields. Glob. Chang. Biol. 2011, 17, 997-1012. [CrossRef]

3. Knox, J.; Daccache, A.; Hess, T.; Haro, D. Meta-analysis of climate impacts and uncertainty on crop yields in Europe. Environ. Res. Lett. 2016, 11, 113004. [CrossRef]

4. Porter, J.; Semenov, M. Crop responses to climatic variation. Philos. Trans. R. Soc. B 2005, 360, $2021-2035$. [CrossRef] [PubMed]

5. Lobell, D.; Bänziger, M.; Magorokosho, C.; Vivek, B. Nonlinear heat effects on African maize as evidenced by historical yield trials. Nat. Clim. Chang. 2011, 1, 42-45. [CrossRef]

6. Xiao, D.; Tao, F. Contributions of cultivars, management and climate change to winter wheat yield in the North China Plain in the past three decades. Eur. J. Agron. 2014, 52, 112-122. [CrossRef]

7. Tao, S.; Shen, S.; Li, Y.; Wang, Q.; Gao, P.; Mugume, I. Projected crop production under regional climate change using scenario data and modeling: Sensitivity to chosen sowing date and cultivar. Sustainability 2016, 8, 214. [CrossRef]

8. Zhang, Q.; Zhang, W.; Li, T.; Sun, W.; Yu, Y.; Wang, G. Projective analysis of staple food crop productivity in adaptation to future climate change in China. Int. J. Biometeorol. 2017, 61, 1445-1460. [CrossRef] [PubMed] 
9. Liu, D.; Zeleke, K.; Wang, B.; Macadam, I.; Scott, F.; Martin, R. Crop residue incorporation can mitigate negative climate change impacts on crop yield and improve water use efficiency in a semiarid environment. Eur. J. Agron. 2017, 85, 51-68. [CrossRef]

10. Tao, F.; Zhang, Z. Climate change, wheat productivity and water use in the North China Plain: A new super-ensemble based probabilistic projection. Agric. For. Meteorol. 2013, 170, 146-165. [CrossRef]

11. Tebaldi, C.; Lobell, D. Estimated impacts of emission reductions on wheat and maize crops. Clim. Chang. 2015, 146, 533-545. [CrossRef]

12. Cammarano, D.; Zierden, D.; Stefanova, L.; Asseng, S.; O’Brien, J.; Jones, J. Using historical climate observations to understand future climate change crop yield impacts in the Southeastern US. Clim. Chang. 2016, 134, 311-326. [CrossRef]

13. IPCC. Climate Change 2013: The Physical Science Basis. Contribution of Working Group I to the Fifth Assesssment Report of the Intergovernmental Panel on Climate Change; Stocker, T.F., Qin, D., Platter, G.K., Tignor, M., Allen, S.K., Boschung, J., Nauels, A., Xia, Y., Bex, V., Midgley, P.M., Eds.; Cambridge University Press: Cambridge, UK; New York, NY, USA, 2013.

14. Yang, M.; Xiao, W.; Zhao, Y.; Li, X.; Huang, Y.; Lu, F.; Hou, B.; Li, B. Assessment of potential climate change effects on the rice yield and water footprint in the Nanliujiang Catchment, China. Sustainability 2018, 10, 242. [CrossRef]

15. Stevens, T.; Madani, K. Future climate impacts on maize farming and food security in Malawi. Sci. Rep. 2016, 6, 36241. [CrossRef] [PubMed]

16. Lizumi, T.; Furuya, J.; Shen, Z.; Kim, W.; Okada, M.; Fujimori, S.; Hasegawa, T.; Nishimori, M. Responses of crop yield growth to global temperature and socioeconomic changes. Sci. Rep. 2017, 7, 7800.

17. Moss, R.H.; Edmonds, J.A.; Hibbard, K.A.; Manning, M.R.; Rose, S.K.; van Vuuren, D.P.; Carter, T.R.; Emori, S.; Kainuma, M.; Kram, T.; et al. The next generation of scenarios for climate change research and assessment. Nature 2010, 463, 747-756. [CrossRef] [PubMed]

18. Taylor, K.; Stouffer, R.; Meehl, G. An overview of CMIP5 and the experiment design. Bull. Am. Meteor. Soc. 2012, 93, 485-498. [CrossRef]

19. Wang, B.; Liu, D.; Macadam, I.; Alexander, L.; Abramowitz, G.; Yu, Q. Multi-model ensemble projections of future extreme temperature change using a statistical downscaling method in south eastern Australia. Clim. Chang. 2016, 138, 85-98. [CrossRef]

20. Wang, B.; Liu, D.; Asseng, S.; Macadam, I.; Yu, Q. Modelling wheat yield change under $\mathrm{CO}_{2}$ increase, heat and water stress in relation to plant available water capacity in eastern Australia. Eur. J. Agron. 2017, 90, 152-161. [CrossRef]

21. Vaittinada Ayar, P.; Vrac, M.; Bastin, S.; Carreau, J.; Déqué, M.; Gallardo, C. Intercomparison of statistical and dynamical downscaling models under the EURO- and MED-CORDEX initiative framework: Present climate evaluations. Clim. Dyn. 2016, 46, 1301-1329. [CrossRef]

22. Wilcke, R.; Mendlik, T.; Gobiet, A. Multi-variable error correction of regional climate models. Clim. Chang. 2013, 120, 871-887. [CrossRef]

23. He, L.; Cleverly, J.; Wang, B.; Jin, N.; Mi, C.; Liu, D.; Yu, Q. Multi-model ensemble projections of future extreme heat stress on rice across southern China. Theor. Appl. Climatol. 2017. [CrossRef]

24. Liu, D.; Zuo, H. Statistical downscaling of daily climate variables for climate change impact assessment over New South Wales, Australia. Clim. Chang. 2012, 115, 629-666. [CrossRef]

25. Tao, F.; Zhang, Z.; Xiao, D.; Zhang, S.; Rötter, R.; Shi, W.; Liu, Y.; Wang, M.; Liu, F.; Zhang, H. Responses of wheat growth and yield to climate change in different climate zones of China, 1981-2009. Agric. For. Meteorol. 2014, 189-190, 91-104. [CrossRef]

26. Xiao, D.; Shen, Y.; Qi, Y.; Moiwo, J.; Min, L.; Zhang, Y.; Guo, Y.; Pei, H. Impact of alternative cropping systems on groundwater use and grain yields in the North China Plain Region. Agric. Syst. 2017, 153, 109-117. [CrossRef]

27. Yang, Y.; Liu, D.; Anwar, M.; Zuo, H.; Yang, Y. Impact of future climate change on wheat production in relation to plant-available water capacity in a semiarid environment. Theor. Appl. Climatol. 2014, 115, 391-410. [CrossRef]

28. Xiao, D.; Cao, J.; Bai, H.; Qi, Y.; Shen, Y. Assessing the impact of climate variables and sowing date on spring wheat yield in the Northern China. Int. J. Agric. Biol. 2017, 19, 1551-1558. 
29. Prescott, J. Evaporation from a water surface in relation to solar radiation. Trans. R. Soc. S. Aust. 1940, 64, 114-118.

30. Jones, C.; Robertsona, E.; Arorab, V.; Friedlingsteinc, P.; Shevliakovad, E.; Boppe, L.; Brovkinf, V.; Hajimag, T.; Katoh, E.; Kawamiyag, M.; et al. Twenty-first-century compatible $\mathrm{CO}_{2}$ emissions and airborne fraction simulated by CMIP5 earth system models under four representative concentration pathway. J. Clim. 2013, 26, 4398-4413. [CrossRef]

31. Wang, B.; Liu, D.; Asseng, S.; Macadam, I.; Yu, Q. Impact of climate change on wheat flowering time in eastern Australia. Agric. For. Meteorol. 2015, 209, 11-21. [CrossRef]

32. Richardson, C.; Wright, D. WGEN: A Model for Generating Daily Weather Variables; U.S. Department of Agriculture, Agricultural Research Service: Washington, DC, USA, 1984.

33. Hammer, G.; van Oosterom, E.; McLean, G.; Chapman, S.; Broad, I.; Harland, P.; Muchow, R. Adapting APSIM to model the physiology and genetics of complex adaptive traits in field crops. J. Exp. Bot. 2010, 61, 2185-2202. [CrossRef] [PubMed]

34. Holzworth, D.P.; Huth, N.I.; deVoil, P.G.; Zurcher, E.J.; Herrmann, N.I.; McLean, G.; Chenu, K.; van Oosterom, E.J.; Snow, V.; Murphy, C.; et al. APSIM-Evolution towards a new generation of agricultural systems simulation. Environ. Model. Soft 2014, 62, 327-350. [CrossRef]

35. Keating, B.; Carberry, P.S.; Hammer, G.L.; Probert, M.E.; Robertson, M.J.; Holzworth, D.; Huth, N.I.; Hargreaves, J.N.G.; Meinke, H.; Hochman, Z.; et al. An overview of APSIM, a model designed for farming systems simulation. Eur. J. Agron. 2003, 18, 267-288. [CrossRef]

36. Liu, D.; Anwar, M.; O'Leary, G.; Conyers, M. Managing wheat stubble as an effective approach to sequester soil carbon in a semi-arid environment: Spatial modelling. Geoderma 2014, 214, 50-61. [CrossRef]

37. Southworth, J.; Randolph, J.; Habeck, M.; Doering, O.; Pfeifer, R.; Rao, D.; Johnston, J. Consequences of future climate change and changing climate variability on maize yields in the midwestern United States. Agric. Ecosyst. Environ. 2000, 82, 139-158. [CrossRef]

38. Tao, F.; Xiao, D.; Zhang, S.; Zhang, Z.; Rotter, R. Wheat yield benefited from increases in minimum temperature in the Huang-Huai-Hai Plain of China in the past three decades. Agric. For. Meteorol. 2017, 239, 1-14. [CrossRef]

39. Lin, E.; Xiong, W.; Ju, H.; Xu, Y.; Li, Y.; Bai, L.; Xie, L. Climate change impacts on crop yield and quality with $\mathrm{CO}_{2}$ fertilization in China. Philos. Trans. R. Soc. B 2005, 360, 2149-2154.

40. Tebaldi, C.; Knutti, R. The use of the multi-model ensemble in probabilistic climate projections. Philos. Trans. R. Soc. A 2007, 365, 2053-2075. [CrossRef] [PubMed]

41. $\mathrm{Xu}, \mathrm{C} . ; \mathrm{Xu}, \mathrm{Y}$. The projection of temperature and precipitation over China under RCP scenarios using a CMIP5multi-model ensemble. Atmos. Ocean. Sci. Lett. 2012, 5, 427-433.

42. Welch, J.; Vincent, J.; Auffhammer, M.; Moya, P.; Dobermann, A.; Dawe, D. Rice yields in tropical/subtropical Asia exhibit large but opposing sensitivities to minimum and maximum temperatures. Proc. Natl. Acad. Sci. USA 2010, 107, 14562-14567. [CrossRef] [PubMed]

43. Juknys, R.; Velicka, R.; Kanapickas, A.; Kriauciuniene, Z.; Masilionyte, L.; Vaguseviciene, I.; Pupaliene, R.; Klepeckas, M.; Sujetoviene, G. Projecting the impact of climate change on phenology of winter wheat in northern Lithuania. Int. J. Biometeorol. 2017, 61, 1765-1775. [CrossRef] [PubMed]

44. Porter, J.; Gawith, M. Temperatures and the growth and development of wheat: A review. Eur. J. Agron. 1999, 10, 23-36. [CrossRef]

45. Jamieson, P.; Brooking, I.; Semenov, M.; Porter, J. Making sense of wheat development: A critique of methodology. Field Crops Res. 1998, 55, 117-127. [CrossRef]

46. Fu, C.; Wen, G. Variation of ecosystems over East Asia in association with seasonal, interannual and decadal monsoon climate variability. Clim. Chang. 2001, 43, 477-494. [CrossRef]

47. Liu, X.; Sun, H.; Feike, T.; Zhang, X.; Shao, L.; Chen, S. Assessing the impact of air pollution on grain yield of winter wheat-A case study in the North China Plain. PLoS ONE 2016, 11, e0162655. [CrossRef] [PubMed]

48. Asseng, S.; Ewert, F.; Martre, P.; Rötter, R.P.; Lobell, D.B.; Cammarano, D.; Kimball, B.A.; Ottman, M.J.; Wall, G.W.; White, J.W.; et al. Rising temperatures reduce global wheat production. Nat. Clim. Chang. 2015, 5, 143-147. [CrossRef]

49. Nonhebel, S. Effects of temperature rise and increase in $\mathrm{CO}_{2}$ concentration on simulated wheat yields in Europe. Clim. Chang. 1996, 34, 73-90. [CrossRef] 
50. Wang, J.; Wang, E.; Yang, X.; Zhang, F.; Yin, H. Increased yield potential of wheat-maize cropping system in the North China Plain by climate change adaptation. Clim. Chang. 2012, 113, 825-840. [CrossRef]

51. Sun, Q.; Kröbel, R.; Müller, T.; Römheld, V.; Cui, Z.; Zhang, F.; Chen, X. Optimization of yield and water-use of different cropping systems for sustainable groundwater use in North China Plain. Agric. Water Manag. 2011, 98, 808-814. [CrossRef]

52. Xiao, D.; Tao, F.; Liu, Y.; Shi, W.; Wang, M.; Liu, F.; Zhang, S.; Zhu, Z. Observed changes in winter wheat phenology in the North China Plain for 1981-2009. Int. J. Biometeorol. 2013, 57, 275-285. [CrossRef] [PubMed]

(C) 2018 by the authors. Licensee MDPI, Basel, Switzerland. This article is an open access article distributed under the terms and conditions of the Creative Commons Attribution (CC BY) license (http://creativecommons.org/licenses/by/4.0/). 